\title{
Editorial
}

\section{Selected Papers from the International Conference on Nuclear Energy for New Europe 2007}

\author{
Igor Jenčič, ${ }^{1}$ Ivo Kljenak, ${ }^{1}$ and Martina Adorni ${ }^{2}$ \\ ${ }^{1}$ Jožef Stefan Institute, 1000 Ljbljana, Slovenia \\ ${ }^{2}$ San Piero a Grado Nuclear Research Group (GRNSPG), Department of Mechanical Nuclear and Production Engineering, \\ University of Pisa, via Diotisalvi 2, 56122 Pisa, Italy
}

Correspondence should be addressed to Martina Adorni, m.adorni@ing.unipi.it

Received 11 December 2008; Accepted 11 December 2008

Copyright (c) 2008 Igor Jenčič et al. This is an open access article distributed under the Creative Commons Attribution License, which permits unrestricted use, distribution, and reproduction in any medium, provided the original work is properly cited.

We are proud to introduce this special issue of the journal "Science and Technology of Nuclear Installations," which is devoted to selected papers from the International Conference "Nuclear Energy for New Europe 2007." The conference was organized by the Nuclear Society of Slovenia and Jožef Stefan Institute, and took place from September 10 to 13, 2007, in Portorož, Slovenia.

Although it began modestly as the yearly meeting of the Nuclear Society of Slovenia, this annual conference has gradually become a truly international meeting of professionals, researchers, academics, members of regulatory bodies, and others involved in the peaceful use of nuclear energy. The International Conference "Nuclear Energy for New Europe 2007" was the 16th in the series. The conference was attended by 175 registered participants from 22 countries. Altogether, 112 papers were presented: 48 orally during plenary sessions and 64 as posters. The conference thus proved again to be an international forum for the exchange of ideas from various topics related to nuclear energy.

This is the first time that extended versions of selected papers from the conference are published in a special issue of an international journal. Although the idea of publishing such a special issue has been discussed for some years, it was not realized until now due to the lack of opportunity. The journal "Science and Technology of Nuclear Installations" proved to be a suitable publication for such an undertaking.

After the closing of the conference, authors of papers, presented at the conference, were invited to submit extended papers for publication in the special issue. Papers that were submitted then went through an extensive peer-review process to ensure a high quality of the publications. As a result, 13 papers are included in this special issue. The papers belong to various topics that were considered at the conference.

We take this opportunity to express our gratitude to the conference organizers, to the members of the program committee who performed the first selection of papers and elaborated the conference program, and the reviewers who contributed to the final form of this special issue. Last but not least, we would like to thank Hindawi Publishing Corporation for offering the possibility for this special issue and the members of its editorial staff for all the assistance they have provided.

Igor Jenčič

Ivo Kljenak

Martina Adorni 

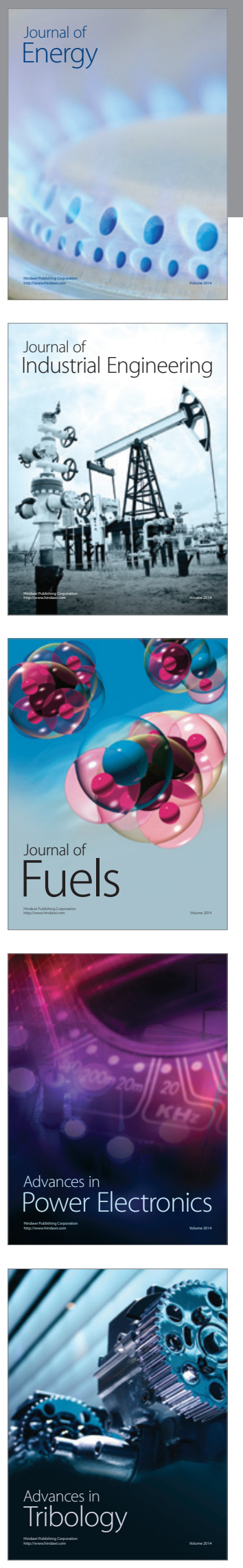
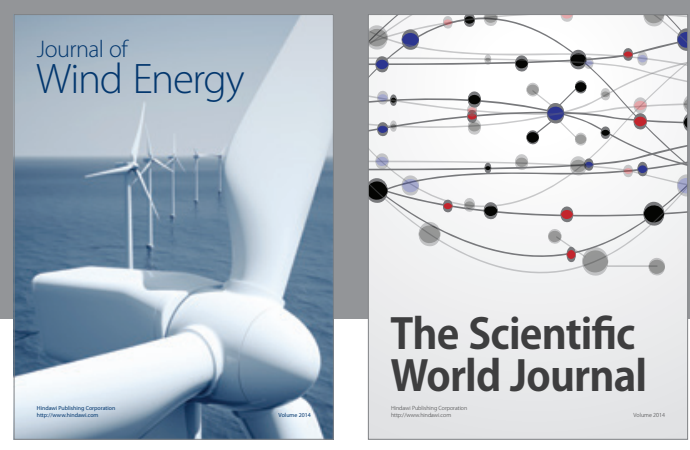

The Scientific World Journal

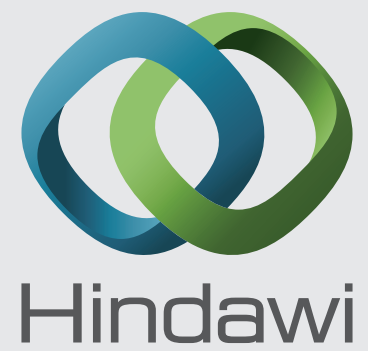

Submit your manuscripts at http://www.hindawi.com
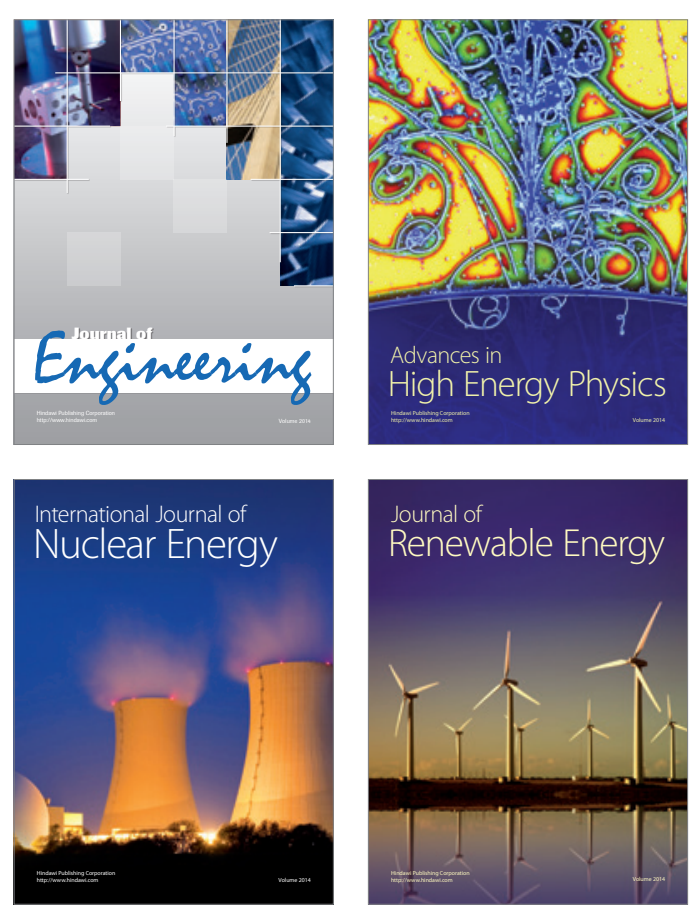

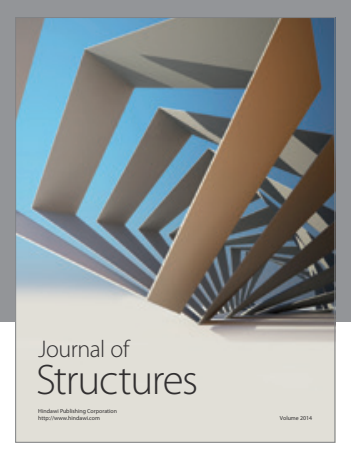

Rotating
Mechinery
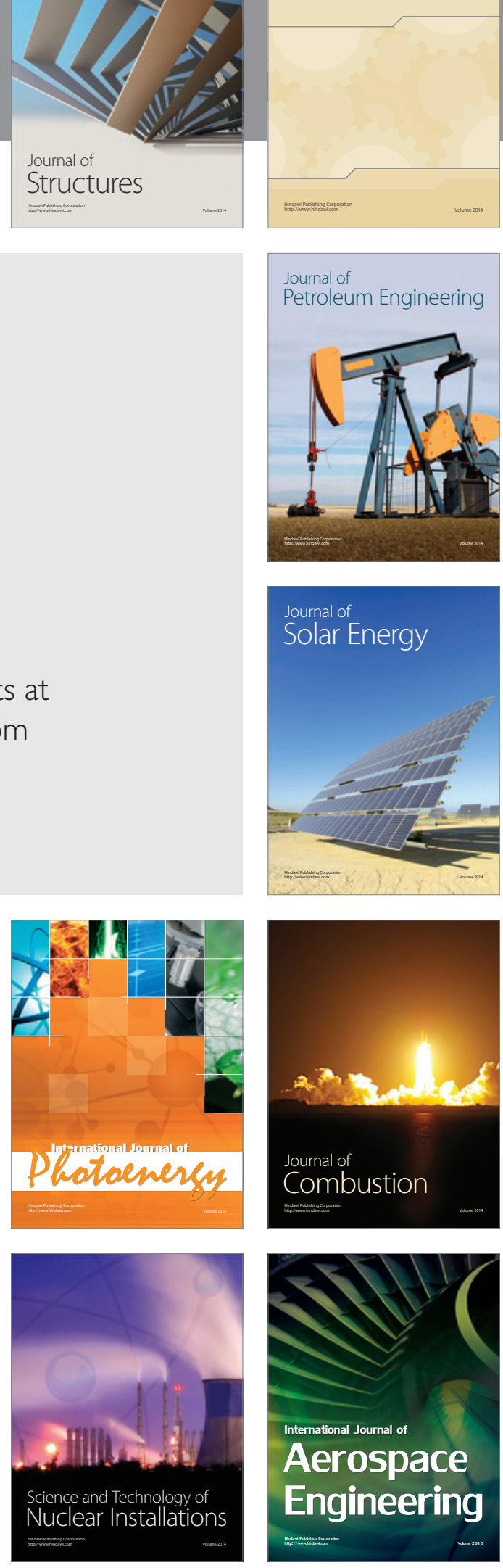